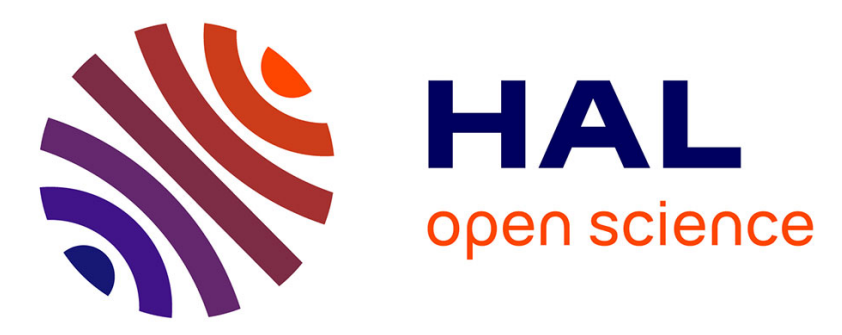

\title{
Patterns of the Ferrocyanide-Iodate-Sulfite Reaction Revisited: The Role of Immobilized Carboxylic Functions
}

\author{
Istvan Szalai, Patrick de Kepper
}

\section{- To cite this version:}

Istvan Szalai, Patrick de Kepper. Patterns of the Ferrocyanide-Iodate-Sulfite Reaction Revisited: The Role of Immobilized Carboxylic Functions. Journal of Physical Chemistry A, 2008, 112 (5), pp.783-786. 10.1021/jp711849m . hal-00617244

\section{HAL Id: hal-00617244 \\ https://hal.science/hal-00617244}

Submitted on 6 Oct 2017

HAL is a multi-disciplinary open access archive for the deposit and dissemination of scientific research documents, whether they are published or not. The documents may come from teaching and research institutions in France or abroad, or from public or private research centers.
L'archive ouverte pluridisciplinaire HAL, est destinée au dépôt et à la diffusion de documents scientifiques de niveau recherche, publiés ou non, émanant des établissements d'enseignement et de recherche français ou étrangers, des laboratoires publics ou privés. 


\title{
Patterns of the Ferrocyanide-Iodate-Sulfite Reaction Revisited: The Role of Immobilized Carboxylic Functions
}

\author{
István Szalai*,† and Patrick De Kepper*,‡ \\ Institute of Chemistry, L. Eötvös University, P.O. Box 32, H-1518 Budapest 112, Hungary, and Centre de \\ Recherche Paul Pascal, CNRS, University of Bordeaux I, Avenue Schweitzer, F-33600 Pessac, France
}

\begin{abstract}
We experimentally demonstrate that the standing lamella reaction-diffusion patterns initially observed 17 years ago in a gel-filled open spatial reactor operated with the ferrocyanide-iodate-sulfite bistable reaction requires an upper critical concentration of low-mobility species with weak acid functional groups, a parameter that was overlooked at the time and had made observations difficult to reproduce. The present approach enables the control of the space scale separation between activatory and inhibitory processes. It makes the wealth of exotic pattern dynamics observed earlier easier to reproduce and understand. This contribution should considerably revive the interest in this reaction and boost the search for the control of reactiondiffusion patterns in other bistable systems.
\end{abstract}

\section{Introduction}

Reaction-diffusion processes in solution chemistry are a leading area of pattern formation ${ }^{1-3}$ far from equilibrium and a paradigm for biological development. ${ }^{4-6}$ In the past two decades, following the development of open spatial reactors, sustained traveling wave patterns have been observed in an increasing number of different reactions. ${ }^{7-12}$ Yet, the observation of standing patterns are still limited to a couple of systems. These are the chlorite-iodide-malonic acid $^{13}$ (CIMA) family of reactions, which made possible the first clear experimental observations $^{8}$ of stationary Turing patterns, and the ferrocyanide-iodate- sulfite $^{14}$ (FIS) reaction, which was shown to produce a large variety of patterns resulting from the interaction of chemical activity fronts, in a spatially bistable system. ${ }^{15-17}$

Though the two patterning reaction systems were discovered about 17 years ago, only the CIMA reaction system was used and further developed by other groups. ${ }^{18-20}$ The chemical and physical mechanisms at play in the patterning processes of this system are well understood and controlled. ${ }^{21-24}$ This was not the case for the FIS system. The gross kinetic mechanism of this reaction is known, ${ }^{25-27}$ but the actual role of the original poly(acrylamide) gel network on the relative diffusion of species inside of the gel was disregarded and uncontrolled. However, most of the observations could be qualitatively accounted for by numerical simulations, ${ }^{16}$ with the assumption that the proton, the main activatory species of this reaction, would diffuse less than the hydrosulfite ion, which acts as the main negative feedback species. ${ }^{17}$ No comprehensive physical argument was initially provided in support of this hypothesis. A priori, protons are the fastest diffusing ions in aqueous solutions.

We show that by introducing, above a critical concentration, controlled amounts of poly(acrylate) in a neutral agarose gel

\footnotetext{
* To whom correspondence should be addressed.

$\dagger$ L. Eötvös University.

$\doteqdot$ University of Bordeaux I.
}

OSFR, one can reproduce the original observations, in particular, the development of standing lamella patterns and spot division dynamics. It is well-established that due to the fast protonation equilibrium, weak acid functions with very low mobility can lead to a selective slowing down of the effective diffusivity of protons. $^{28,29}$

\section{Experimental Section}

Two geometries of OSFR were used in this report. One consists of a transparent thin disc (22 $\mathrm{mm}$ diameter and 0.75 $\mathrm{mm}$ thick) made of $4 \%$ agarose gel (Fluka 05070.) One face of the disc is in direct contact with the contents of a stirred tank reactor (CSTR) through a circular hole (18 $\mathrm{mm}$ diameter) in mask which holds the gel tightly immobilized against an observation window. Beyond the contact surface, the disc extends ( $2 \mathrm{~mm}$ ) under the mask (for details, see ref 23). Patterns are observed by transparency and are monitored by a CCD video camera connected to a video tape recorder and to a black and white frame grabber board. The observations provide information on light transmission patterns across the feed surface but not on how these changes organize in the thickness of the disc. Such complementary information is provided by observations in a flat annular gel reactor $(1 \mathrm{~mm}$ deep and $25 \mathrm{~mm}$ outer diameter). All of the faces of the annulus are tightly pressed against impermeable walls, except for the outer edge, which is in direct contact with the contents of a CSTR (for details, see ref 11). The observations are made in a direction orthogonal to the feed surface and thus allow solving of the color changes in the feed direction. All reported experiments were made at 30 ${ }^{\circ} \mathrm{C}$ with a residence time of the CSTR of $\tau=250 \mathrm{~s}$. The chemical solutions are stored in three separated reservoirs and injected by precision pumps with equal flow rates at the base of the CSTR, in the close vicinity of a turbine rotating at 1000 $\mathrm{rpm}$. An overflow pipe maintains the reaction volume constant and at room pressure, with no air interface. The respective 
reservoirs contain (1) potassium iodate (Fluka), (2) sodium sulfite (Fluka), potassium ferrocyanide (Acros Organics), and sodium poly(acrylate) (Aldrich, MW:15 000 Dalton), and (3) sulfuric acid (Roth). In the disc reactor experiments, bromothymol blue, a $\mathrm{pH}$ color indicator which switches from blue to yellow in the $7.6-6.2 \mathrm{pH}$ range, is added $(0.3 \mathrm{~g} / \mathrm{L})$ in reservoirs 1 and 2, while bromocresol green is used at the same concentration in the annular reactor. This $\mathrm{pH}$ indicator switches from blue to light yellow in the 5.4-3.8 $\mathrm{pH}$ range. All of the chemicals are analytical, grade and solutions are prepared in deionized water. The feed concentration ${ }^{30}$ of potassium iodate $\left[\mathrm{KIO}_{3}\right]_{0}$, sodium sulfite $\left[\mathrm{Na}_{2} \mathrm{SO}_{3}\right]_{0}$, and $\left[\mathrm{K} 4 \mathrm{Fe}(\mathrm{CN})_{6}\right]_{0}$ were fixed at 75,89 , and $20 \mathrm{mM}$, respectively. The feed concentrations of the other species are changed during the experiments and are indicated where appropriate. For each new poly(acrylate) (PA) feed concentration, the gel pieces are left to impregnate in a solution with the targeted value, for at least $24 \mathrm{~h}$.

\section{Experimental Results}

In the range of the chemical feed parameter used in this report, the CSTR contents exhibit bistability between a high $\mathrm{pH}(6-$ 8) flow branch and a low $\mathrm{pH}(3.5-4.0)$ thermodynamic branch. ${ }^{14}$ The contents of the CSTR were always maintained on the flow branch. In these conditions, two types of color profiles can be observed across the annular reactor. The annulus is either uniformly blue (as the contents of the CSTR), indicating that the $\mathrm{pH}$ never drops below 5.4, or exhibits a sharp color change from blue, at the contact with the CSTR, to pale yellow in the deepest part, as illustrated in Figure 1A and B. The uniform and mixed color states will be referred to, respectively, as the $\mathrm{F}$ and $\mathrm{M}$ states. In the same conditions, the color of the disc reactor appears either uniformly blue or uniformly brownish blue-green; these two states cannot always be distinguished by their simple gray level in the figures, but their interfaces always exhibit a sharp change in gray intensity. Nevertheless, in stationary patterns, the $\mathrm{M}$ state domains are always clearer than those of the F state. Pattern development sensitively depends on the sulfuric acid feed concentration, which is conveniently used as a control parameter.

In the disc reactor, in the absence of PA and at low $\left[\mathrm{H}_{2} \mathrm{SO}_{4}\right]_{0}$ (e.g., $2.92 \mathrm{mM}$ in Figure 1A), traveling domains of the $\mathrm{M}$ state in the majority $\mathrm{F}$ state are observed. These domains are delimited by acid-producing " $(+)$ fronts" $(\mathrm{M} \rightarrow \mathrm{F}$ state transition) and acid-consuming " $(-)$ fronts" (F $\rightarrow$ M state transition). In Figure 2, the $(+)$ and $(-)$ fronts are, respectively, distinguished by a sharp change to a bright $\mathrm{M}$ state braid and to a darker $\mathrm{F}$ state zone. Starting with the spatial reactor uniformly in the F state at $\left[\mathrm{H}_{2} \mathrm{SO}_{4}\right]_{0}=2.80 \mathrm{mM}$, a supercritical increase of $\left[\mathrm{H}_{2} \mathrm{SO}_{4}\right]_{0}$ to $2.92 \mathrm{mM}$ leads to the spontaneous development of initially growing domains of the $\mathrm{M}$ state at some pacemaker regions close to the rim of the mask but never in direct contact with the contents of the gel under the mask (e.g., the bright region at 4 o'clock in Figure 2A). This is remarkable since by the time this $\mathrm{M}$ state domain develops, the composition under the mask is acidic - the extent of the reaction is naturally always greater than that in the parts directly in contact with the CSTR. The new M state domain starts to expand in all directions, but in the radial direction, this expansion soon stops at a finite distance from the mask. The initial (+)front "bounces", that is, changes sign. This front reversal occurs all along the rim of the mask as the $(+)$ front travels across the disc. This is a generic phenomenon in the present experiments. The front reversal leads to a recovery of the $\mathrm{F}$ state, thus limiting the initial expansion of the $M$ state. As the $M$ state domain

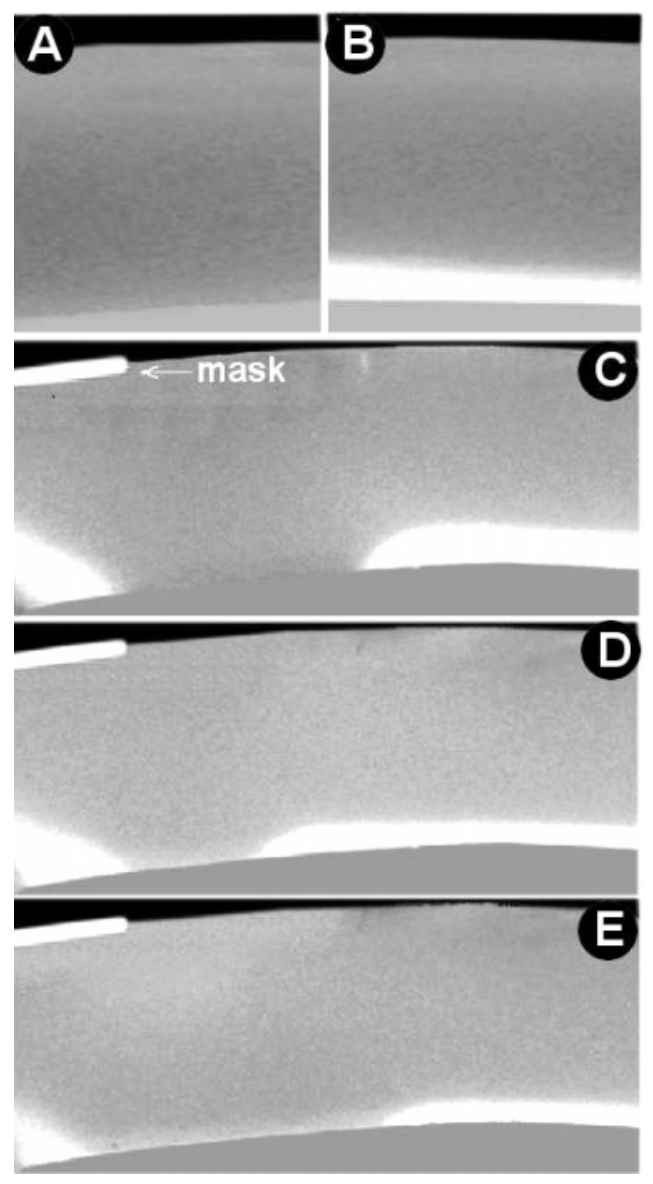

Figure 1. Stationary state $F(A)$ and $M(B)$ states and the front interaction $(\mathrm{C}-\mathrm{E})$ observed in the annular OSFR at $\left[\mathrm{H}_{2} \mathrm{SO}_{4}\right]_{0}=3.09$ $\mathrm{mM}$. The upper part of the gel strip is in contact with the CSTR contents (black), and the bottom is an impermeable wall (light gray). In between, the gray scale changes from medium to white correspond to the $\mathrm{pH}$ color indicator changes in the gel. On snapshots $\mathrm{C}-\mathrm{E}$, the left part of the annular gel is masked, and there is no direct contact with the CSTR. The location of the mask is indicated by a white stripe.

travels away, a new patch of $\mathrm{M}$ state forms periodically. As a result, except for a narrow ring area in the vicinity of the mask, every space point of the disc undergoes large amplitude oscillations with a period of $\sim 20 \mathrm{~min}$. To understand the front bouncing phenomenon and the associated changes in their aspects, we glued a mask over a small part of an annular OSFR. The observations are summarized in Figure $1 \mathrm{C}-\mathrm{E}$. The acidproducing front (Figure 1C) exhibits a small overshoot in the radial direction of the growing acid core, while the acidconsuming front Figure 1E shows a weaker drop. Noticeably, when the $\mathrm{M}$ state approaches the mask, the acid composition under the mask slightly grows before the front propagation reverses sign. The pattern developments of the system are governed by the interactions (connection, collision, pairing) between these two types of fronts and eventually by their curvature in the disc reactor.

Let us now describe the gross features of these interactions and their evolution as a function of $[\mathrm{PA}]_{0}{ }^{32}$ and $\left[\mathrm{H}_{2} \mathrm{SO}_{4}\right]_{0}$ in the disc reactor. In the absence of PA and at low $\left[\mathrm{H}_{2} \mathrm{SO}_{4}\right]_{0}$, fronts of the same sign annihilate upon head-on collision, while a head-to-back interaction between fronts of opposite sign can make the $(+)$ front change sign. The connections between fronts of opposite sign along the contour of an $\mathrm{M}$ state domain can become the center of broad, low-curvature, rotating spiral waves, as illustrated in Figure $2 \mathrm{~B}$. At a fixed $\left[\mathrm{H}_{2} \mathrm{SO}_{4}\right]_{0}$ value, front repulsion and pairing phenomena develop first between (-)- 

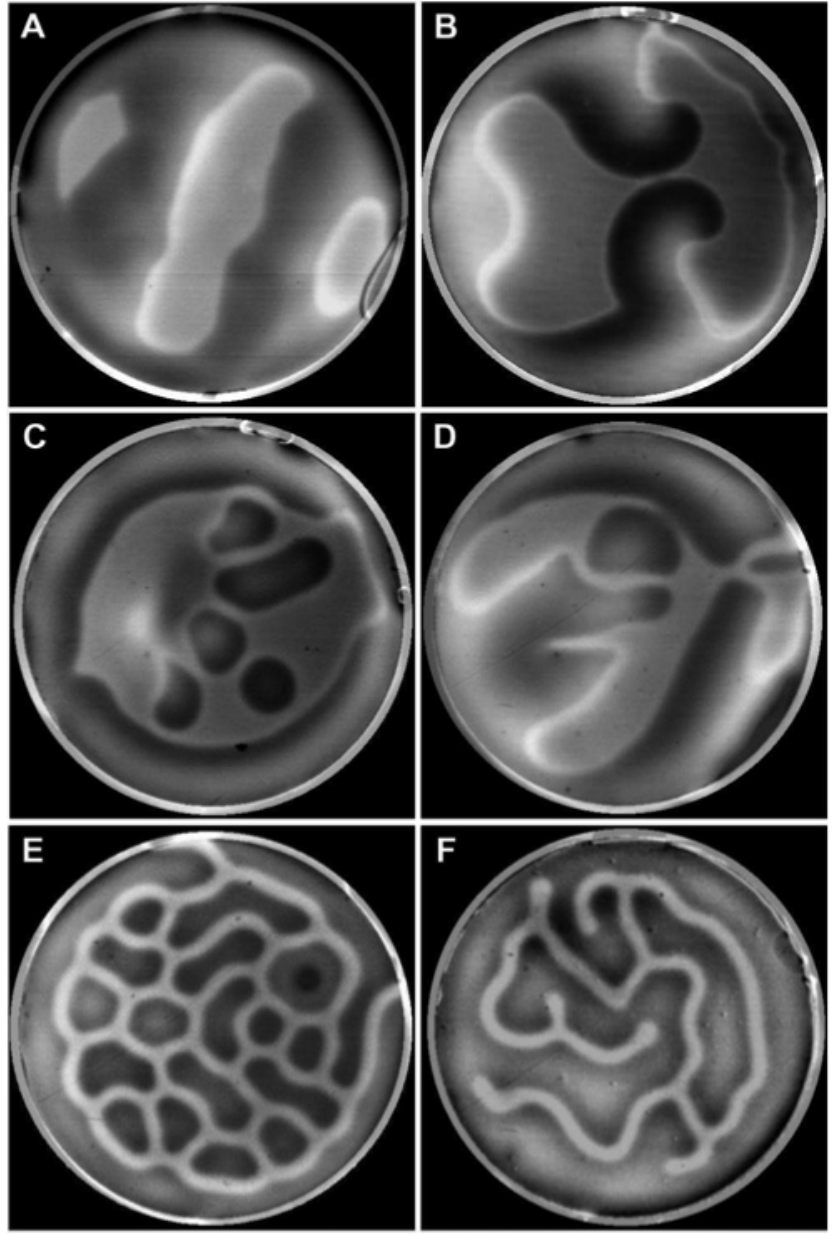

Figure 2. Patterns observed in the disk OSFR: (A) travelling M state domains, (B) double spiral wave pattern, (C) dynamic F state spot pattern in a large $\mathrm{M}$ state domain, in the absence of PA at $\left[\mathrm{H}_{2} \mathrm{SO}_{4}\right]_{0}$ values of $2.92,2.97$, and $3.04 \mathrm{mM}$, (D) mixture of traveling waves and unstable filament structures at $[\mathrm{PA}]_{0}=0.5 \mathrm{mM}$ and $\left[\mathrm{H}_{2} \mathrm{SO}_{4}\right]_{0}=$ $3.04 \mathrm{mM}$, (E) stationary pattern at $[\mathrm{PA}]_{0}=1.0 \mathrm{mM}$ and $\left[\mathrm{H}_{2} \mathrm{SO}_{4}\right]_{0}=$ $3.04 \mathrm{mM}$; (F) stationary pattern at $[\mathrm{PA}]_{0}=4.0 \mathrm{mM}$ and $\left[\mathrm{H}_{2} \mathrm{SO}_{4}\right]_{0}=$ $2.92 \mathrm{mM}$ (for gray scale explanations, see the text).

fronts and produce $\mathrm{M}$ state filaments. At $[\mathrm{PA}]_{0}=0.5 \mathrm{mM}$ (carboxylate function unit), ${ }^{32}$ these filaments are short-lived; they break or swell again by reversing the front sign, and a complex changing mixture of filaments and large traveling domains of $\mathrm{M}$ state results, as illustrated Figure 2D. At the same acid feed concentration but for $[\mathrm{PA}]_{0}=1 \mathrm{mM}$, a stable state $\mathrm{M}$ network pattern ultimately settles (Figure 2E). In the absence of PA, the increase of $\left[\mathrm{H}_{2} \mathrm{SO}_{4}\right]_{0}$ also favors the development of $\mathrm{M}$ state filaments (Figure 2C), but this is not enough to stabilize them even at $[\mathrm{PA}]_{0}=0.5 \mathrm{mM}$. Repulsions between colliding $(+)$ fronts only become manifest at $[\mathrm{PA}]_{0}=4 \mathrm{mM}$. As a result, less-interconnected stationary $\mathrm{M}$ state filament patterns develop (Figure 2F).

At some high-enough acid value, dynamic $\mathrm{F}$ state spot patterns are observed. Contrary to the $\mathrm{M}$ state, the $\mathrm{F}$ state never spontaneously grows a "bubble" in the middle of the other state. Patterns, as that of Figure 2C, are the result of initial trapping between growing domains of the $\mathrm{M}$ state. After this trapping, the F state "bubble" can develop an autonomous dynamics of spot periodic breathing or division and eventually die by overgrowth with the spontaneous emergence of the $M$ state in the middle. The capacity of these bubbles to survive and multiply is favored by the increase of $[\mathrm{PA}]_{0}$. In all of the present experiments, the system has an oscillatory character which is eventually quenched by the development of a dense enough net of $\mathrm{M}$ state filaments.

\section{Discussion}

In the domain of the parameter explored, ${ }^{31}$ no stationary patterns are observed if the agarose gel network is not impregnated by PA above a critical value between 0.5 and 1 $\mathrm{mM}$ (acrylate units). This provides a comprehensive explanation for the origin of the necessary differential diffusion mechanism at play in the development of the stationary patterns. The poorly mobile weak acid functions on the polymer chains induce a direct effective slowing down of the protons by temporarily immobilizing these fast-diffusing species through fast reversible protonation of these functions.

We think that such conditions were easily met in the original experiments with poly(acrylamide) gels. It is known that the amide functions can be readily hydrolyzed into carboxylate functions in alkaline solutions. ${ }^{33,34}$ In standard poly(acrylamide) gels, the amide units are in a molar concentration, and only a few tenths of a percent need to be hydrolyzed to generate the supercritical millimolar amounts of carboxylate functions. This explanation, supported by experiments, is more robust than others previously proposed. ${ }^{35}$

This improved approach with a neutral gel matrix, ${ }^{36}$ which does not degrade over periods of time on the order of the week and which can be loaded with controlled amounts of lowmobility acid functions, makes pattern development in the FIS reaction easier to handle and to suitably model. Our results should trigger a revival of studies in this reaction, where a whole zoo of exotic dynamics dominated by front multiplicity, boundary interactions, and curvature effects is awaiting further experimentation.

Acknowledgment. I.S. is thankful for the support of OTKA (F049666, K67701). P.D.K. is supported by CNRS and the French Agence Nationale de la Recherche.

Supporting Information Available: The movie shows the wave propagation observed in the iodate-sulfite-ferrocyanide reaction in the absence of poly(acrylate) and the formation of standing lamella patterns in the presence of $4 \mathrm{mM}$ poly(acrylate). The period of oscillations in the first clip is approximately 20 min. In the second part, the time is accelerated towards the end of the clip by a factor of 4 . The real time duration of the second clip is $2 \mathrm{~h}$. This material is available free of charge via the Internet at http://pubs.acs.org.

\section{References and Notes}

(1) . Field, R. J., Burger, M., Eds. Oscillations and Traveling Waves in Chemical Systems; Wiley: New York, 1985.

(2) Kapral, R., Showalter, K., Eds. Chemical Patterns and Waves; Kluwer Academic Publisher: Amsterdam, The Netherlands, 1995.

(3) Epstein, I. R.; Pojman, J. An Introduction to Nonlinear Chemical Dynamics; Oxford University Press: New York, 1998.

(4) Turing, A. Phil. Trans. R. Soc. 1952, 237, 37.

(5) Murray, J. D. Mathematical Biology; Field, R. J., Burger, M., Eds. Springer: New York, 2004.

(6) Meinhardt, H. Models of Biological Pattern Formation; Academic Press: London, 1982.

(7) Nozsticzius, Z.; Horsthemke, W.; McCormick, W. D.; Swinney, H. L.; Tam, W. Y. Nature 1987, 329, 619.

(8) Castets, V.; Dulos, E.; Boissonade, J.; De Kepper, P. Phys. Rev. Lett. 1990, 24, 2953.

(9) Lee, K. J.; McCormick, W. D.; Ouyang, Q.; Swinney, H. L. Science 1993, 261, 192

(10) Boissonade, J.; Dulos, E.; Gauffre, F.; Kuperman, M. N.; De Kepper, P. Faraday Discuss. 2001, 120, 353.

(11) Szalai, I.; De Kepper, P. Phys. Chem. Chem. Phys. 2006, 8, 1105

(12) Virányi, Z.; Szalai, I.; Boissonade, J.; De Kepper, P. J. Phys. Chem. A 2007, 111, 8090 . 
(13) De Kepper, P.; Epstein, P.; Kustin, K.; Orbán, M. J. Phys. Chem. 1982, 86,170 .

(14) Edblom, E. C.; Orbán, M.; Epstein, I. R. J. Am. Chem. Soc. 1986 108, 2826.

(15) Lee, K. J.; McCormick, W. D.; Ouyang, Q.; Swinney, H. L. Science 1993, 261, 192

(16) Lee, K. J.; McCormick, W. D.; Pearson, J. E.; Swinney, H. L. Nature 1994, 369, 6477.

(17) Lee, K. J.; Swinney, H. L. Phys. Rev. E 1995, 51, 1899.

(18) (a) Vigil, R. D.; Ouyang, Q.; Swinney, H. L. Physica A 1992, 188 17. (b) Ouyang, Q.; Noszticzius, Z.; Swinney, H. L. J. Phys. Chem. 1992, 96, 6773.

(19) (a) Epstein, I. R.; Lengyel, I.; Kádár, S.; Kagan, M.; Yokoyama, M. Physica A 1992, 188, 26. (b) Dolnik, M.; Berenstein, I.; Zhabotinsky, A. M.; Epstein, I. R. Phys. Rev. Lett. 2001, 87, 238301.

(20) Rudiger, S.; Miguez, D. G.; Munuzuri, A. P.; Sagues, F.; Casademunt, J. Phys. Rev. Lett. 2003, 90, 128301.

(21) Lengyel, I.; Epstein, I. R. Proc. Natl. Acad. Sci. U.S.A. 1992, 89 3977.

(22) Perraud, J. J.; Agladze, K.; Dulos, E.; De Kepper, P. Physica A 1992, 188,1 .

(23) Rudovics, B.; Barillot, E.; Davies, P. W.; Dulos, E.; Boissonade, J.; De Kepper, P. J. Phys. Chem. 1999, 103, 1790.

(24) Davies, P. W.; Blanchedeau, P.; Dulos, E.; De Kepper, P. J. Phys. Chem. A 1998, 102, 8236.

(25) Edblom, E. C.; Györgyi, L.; Orbán, M.; Epstein, I. R. J. Am. Chem. Soc. 1987, 109, 4876 .
(26) (a) Gáspár, V.; Showalter, K. J. Am. Chem. Soc. 1987, 109, 4869 (b) Gáspár, V.; Showalter, K. J. Phys. Chem. 1990, 94, 4973.

(27) Rábai, Gy.; Kaminaga, A.; Hanazaki, I. J. Phys. Chem. 1995, 99 , 9795.

(28) (a) Horváth, D.; Tóth, Á. J. Chem. Phys. 1998, 108, 1447. (b) Jakab, E.; Horváth, D.; Tóth, Á.; Merkin, J. H.; Scott, S. K. Chem. Phys. Lett. 2001, 342, 317

(29) Szalai, I.; Gauffre, F.; Labrot, V.; Boissonade, J.; De Kepper, P. J. Phys. Chem. A 2005, 109, 7843.

(30) [ ] denotes the concentration that the input species would have after mixing and prior to any reaction.

(31) $\left[\mathrm{KIO}_{3}\right]_{0}=75 \mathrm{mM},\left[\mathrm{Na}_{2} \mathrm{SO}_{3}\right]_{0}=89 \mathrm{mM}, 5 \mathrm{mM} \leq\left[\mathrm{K} 4 \mathrm{Fe}(\mathrm{CN})_{6}\right]_{0}$ $\geq 60 \mathrm{mM}, 0 \mathrm{mM} \leq\left[\mathrm{H}_{2} \mathrm{SO}_{4}\right]_{0} \geq 4,17 \mathrm{mM}$, and $22{ }^{\circ} \mathrm{C} \leq$ temperature $\geq 35$ ${ }^{\circ} \mathrm{C}$.

(32) Concentration of carboxylic groups introduced by the poly(acrylate) polymer chains.

(33) Tanaka, T.; Fillmore, D.; Sun, S. T.; Nishio, I.; Swislaw, G.; Shah, A. Phys. Rev. Lett. 1980, 45, 1636.

(34) Sandler, S. R.; Karo, W. Polymer Synthesis; Academic: New York, 1977; Vol. II.

(35) Strier, D. E.; Ponce Dawson, S. J. Chem. Phys. 2000, 112, 825.

(36) It was reported ${ }^{15}$ that similar patterns could be observed using only agar gels, but agar gels are not neutral. They are a mixture of about $70 \%$ agarose (uncharged polysaccharide) and 30\% agaropectin (a sulfonated polysaccharide) and other charged substituents such as D-glucuronic acid. Protons would naturally also exhibit low effective diffusivity in such gels. 